\title{
Distribution of Myeloid-Derived Suppressor Cells in Rheumatoid Arthritis and Sjögren's Syndrome
}

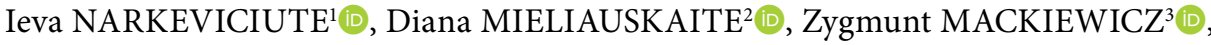

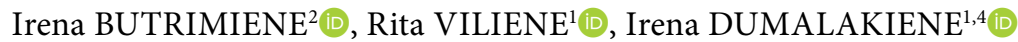

${ }^{1}$ Department of Immunology, State Research Institute Centre For Innovative Medicine, Vilnius, Lithuania

${ }^{2}$ Department of Innovative Diagnostic, State Research Institute Centre For Innovative Medicine, Vilnius, Lithuania

${ }^{3}$ Department of Regenerative Medicine, State Research Institute Centre For Innovative Medicine, Vilnius, Lithuania

${ }^{4}$ Department of Chemistry and Bioengineering, Vilnius Gediminas Technical University, Vilnius, Lithuania

\begin{abstract}
Objectives: This study aims to investigate the distribution of myeloid-derived suppressor cells (MDSCs) in patients with primary or secondary Sjögren's syndrome (SS) or rheumatoid arthritis (RA) in order to better understand MDSCs significance in the pathogenesis of these autoimmune diseases.

Patients and methods: We examined the frequency and calculated absolute counts of overall MDSCs (human leukocyte antigen-antigen D related

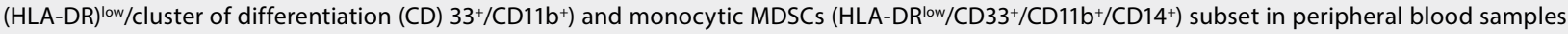
of 23 RA ( 5 males, 18 females; mean age 57 years; range 41 to 81 years), 25 primary Sjögren's syndrome (pSS) (1 male, 24 females; mean age 56 years; range 32 to 77 years), 17 secondary Sjögren's syndrome (sSS) (1 male, 16 females; mean age 60 years; range 49 to 73 years) and 23 nonautoimmune sicca syndrome (nSS) (23 females; mean age 59 years; range 44 to 92 years) patients by flow cytometric analysis.

Results: Analysis revealed that the frequency of overall MDSCs increased in RA group (46.5 \pm 3.4 ) compared with nSS group (35.6 $\pm 3.2 ; p=0.0322$ ). An increase of absolute count of overall MDSCs was most evident in both RA (4383 \pm 456.8 ) and sSS groups ( $3890 \pm 495.7)$ compared with pSS (2447 \pm 275.1 ; $p=0.0002$ and 0.0067$)$ and $n S S$ groups $(2025 \pm 218.1 ; p<0.0001$ and $p=0.0012)$. The highest absolute count of monocytic MDSCs also manifested in RA group (195.4 \pm 39.0$)$, compared with all the other groups $(86.0 \pm 24.9 ; p=0.0002[p S S], 128.5 \pm 53.4 ; p=0.0076[s S S], 83.7 \pm 19.0 ; p=0.0136[n S S])$.

Conclusion: To summarize, we have determined that the most prominent increase of both total and monocytic MDSCs was evident in RA and sSS groups, which leads us to believe that MDSCs are associated with rheumatic processes.

Keywords: Flow cytometry; myeloid-derived suppressor cells; rheumatoid arthritis; Sjögren's syndrome.
\end{abstract}

In recent years, more attention has been paid to myeloid-derived suppressor cells (MDSCs) and their importance in cancer and other illnesses. Increasing numbers of studies suggest that the expansion of these regulatory cells may be a common response to various forms of inflammation. ${ }^{1}$
Myeloid-derived suppressor cells are defined as heterogeneous cell population and they include myeloid progenitor and immature myeloid cells. In steady state, MDSCs reside mostly in bone marrow, but in presence of various pathological conditions, they can expand and be detected in peripheral lymphoid and cancerous tissues, blood

Received: January 02, 2018 Accepted: April 02, 2018 Published online: August 16, 2018

Correspondence: Irena Dumalakiene. Department of Immunology, State Research Institute Centre For Innovative Medicine, 08406, Vilnius, Lithuania. Tel: +370 61626571 e-mail: irena.dumalakiene@imcentras.It 
stream, the spleen and inflammatory sites. ${ }^{2,3}$ Due to their heterogeneity both in morphology and function, MDSCs lack one specific marker of identification. ${ }^{4}$

In murine models, researchers characterize MDSCs by the expression of granulocytedifferentiation antigen (Gr-1) and Crohn's disease (CD) $11 \mathrm{~b}$ markers which represent a mixture of immature myeloid cells, myeloid progenitor cells, monocytes-macrophages, immature granulocytes and dendritic cells. ${ }^{5,6}$ Both murine and human MDSCs can be subdivided into more monocytic and more granulocytic subtypes. Human MDSCs are divided into $\mathrm{CD} 14^{+}$monocytic and $\mathrm{CD} 15^{+}$ granulocytic subtypes. Both of the subtypes express myeloid specific markers CD11b and CD33, but lack the expression of human leukocyte antigen-antigen D related (HLA-DR) and other mature myeloid cells markers. ${ }^{4}$

A majority of research on MDSCs is performed in terms of cancer; however, it is already known that MDSCs are involved in various autoimmune diseases such as systemic lupus erythematosus, ${ }^{7}$ autoimmune type 1 diabetes, ${ }^{8}$ autoimmune hepatitis, ${ }^{9}$ and also in viral, ${ }^{10}$ bacterial ${ }^{11}$ and parasitic $^{12}$ infections, sepsis, ${ }^{13}$ inflammation ${ }^{14}$ or other pathological conditions. ${ }^{15}$ There are limited data available concerning MDSCs in case of rheumatoid arthritis (RA) and no data in case of Sjögren's syndrome (SS). Fujii et al. ${ }^{16}$ showed that in a collagen-induced arthritis (CIA) mouse model, MDSC lowered the number of $\mathrm{T}$ helper cells and suppressed the progression of CIA. The findings of MDSCs as immune response suppressors, functioning directly or indirectly through the induction of regulatory $\mathrm{T}$ cells, are summarized in a review article of Greten et al. ${ }^{4}$ Therefore, in this study, we aimed to investigate the distribution of MDSCs in patients with primary or secondary SS or RA in order to better understand MDSCs significance in the pathogenesis of these autoimmune diseases.

\section{PATIENTS AND METHODS}

Patients who participated in the study were recruited from the Rheumatology Centre of Vilnius University Hospital Santaros Klinikos between September 2014 and December 2016. Of the patients included, 25 (1 male, 24 females; mean age 56 years; range 32 to 77 years) had primary Sjögren's syndrome (pSS), 17 (1 male, 16 females; mean age 60 years; range 49 to 73 years) had secondary Sjögren's syndrome (sSS) due to RA, 23 (5 males, 18 females; mean age 57 years; range 41 to 81 years) had RA and 23 (23 females as control group; mean age 59 years; range 44 to 92 years) had nonautoimmune sicca syndrome (nSS). The diagnoses of pSS and sSS were based on the criteria defined by the American-European Consensus Group criteria for SS. ${ }^{17} \mathrm{RA}$ was diagnosed according to 2010 American College of Rheumatology (ACR)/European League Against Rheumatism (EULAR) criteria for RA. ${ }^{18}$ None of the patients in the control group met the SS classification criteria and they were classified as patients with nSS. All study participants underwent extensive serological evaluation (Table 1). None of the patients was on immunosuppressive medications at the time of the study. A written informed consent was obtained from each subject. The study protocol was approved by the Ethics Committee for Biomedical Research in Vilnius region (2014-05-20, No. 158200-14-733-248). The study was conducted in accordance with the principles of the Declaration of Helsinki.

Multicolor flow cytometric analysis was carried out to determine the frequency of MDSC. The following anti-human monoclonal antibodies were used in the study: anti-CD14 (phycoerythrin [PE]), anti-CD11b (fluorescein isothiocyanate [FITC]), anti-CD33 (allophycocyanin [APC]), antiHLA-DR (peridinin chlorophyll protein complex [PerCP]) (all from BioLegend, San Diego, CA, USA). $50 \mu \mathrm{L}$ of heparinized venous blood was stained with appropriate amounts of monoclonal antibodies (according to manufacturer's recommendations) in flow cytometric test tubes. Cell dyeing protocol was carried out as described previously ${ }^{19}$ and analyzed using FACSCalibur flow cytometer (BD Biosciences, San Jose, CA, USA) and CELLQuest software (BD Biosciences, San Jose, CA, USA). Flow cytometric gating strategy of total and monocytic MDSCs (mMDSCs) in one patient is presented in Figure 1.

Serum samples of study participants were stored at $-80^{\circ} \mathrm{C}$ until analysis. Serum anti-Sjögren's syndrome-related antigen A (anti-Ro/SSA) and anti-Sjögren's syndromerelated antigen $B$ (anti-La/SSB) specific 


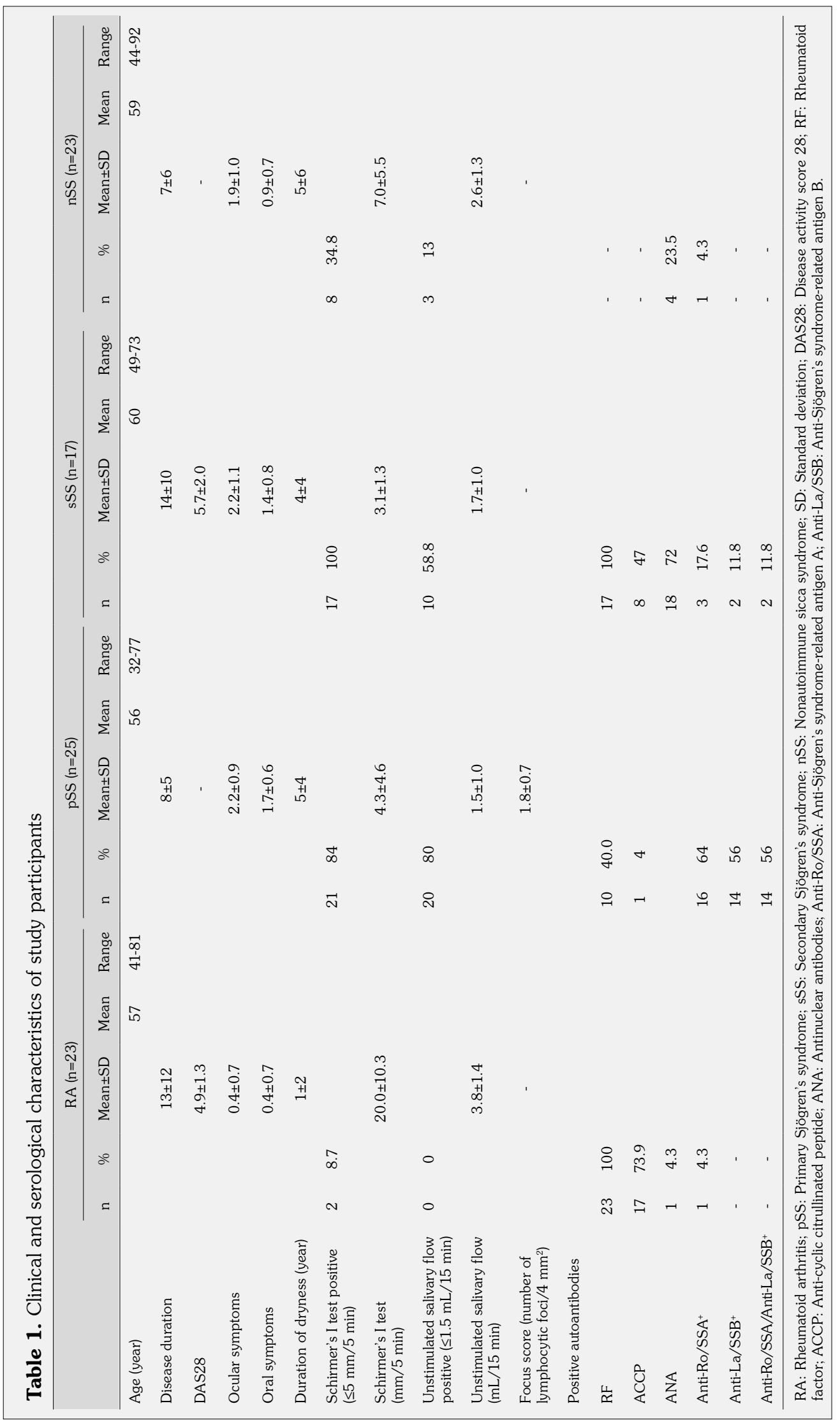


antibody levels were measured by enzymelinked immunosorbent assay (ELISA) by use of the Anti-SSA (Ro) antibodies enzyme immunoassay and Anti-SSB (La) antibodies enzyme immunoassay kits (BioSystems S.A., Barcelona, Spain) according to manufacturer's recommendations. The absorbance of samples was read at $450 \mathrm{~nm}$ with microplate reader (BioTek Instruments Inc., Winooski, VT, USA). The concentration of antibodies present in the sample was calculated by interpolating the absorbance in four parametric calibration curve using Gen5 Microplate Data Collection \& Analysis Software (BioTek Instruments Inc., Winooski, VT, USA). Concentration of anti-Ro/SSA and anti$\mathrm{La} / \mathrm{SSB}$ antibodies in serum sample greater than $12.5 \mathrm{U} / \mathrm{mL}$ was considered positive.

\section{Statistical analysis}

Mann-Whitney $U$ test was performed to determine the statistical differences using GraphPad Prism 6.0 software (GraphPad Software, San Diego, CA, USA). The data are expressed as mean \pm standard error of the mean. Correlations were determined with Spearman rank correlation tests. $P$ values less than 0.05 were considered statistically significant.

\section{RESULTS}

The median frequency of total MDSCs within leukocytes in RA group $(46.5 \pm 3.4)$ was significantly increased compared to control
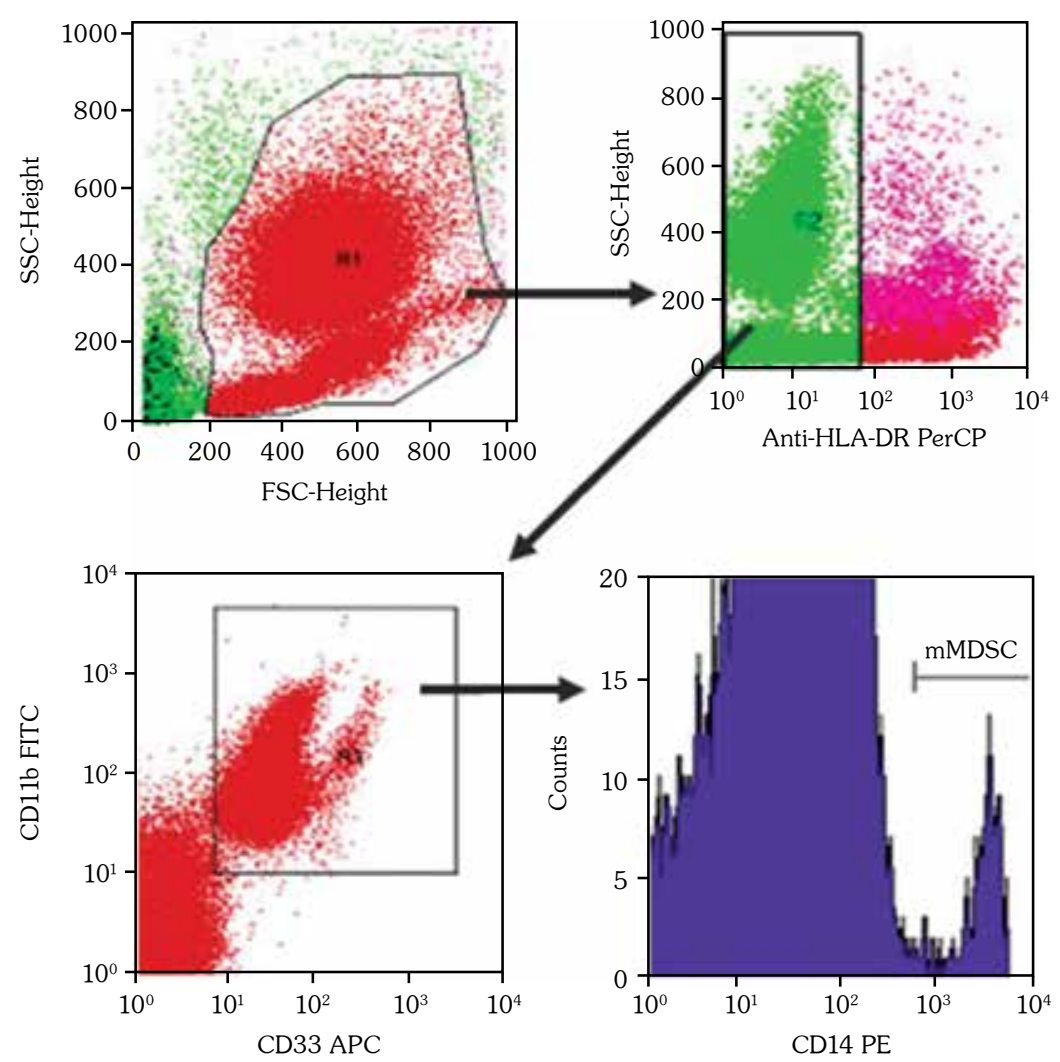

Figure 1. Flow cytometric analysis of total and monocytic MDSC. Whole blood samples were stained with FITC-conjugated anti-CD11b, PerCP-conjugated antiHLA-DR, PE-conjugated anti-CD14 and APC-conjugated anti-CD33. Cells were gated on leukocytes (R1) according to forward- and side-scatter properties. The gating strategy is shown for the HLA-DR ${ }^{\text {low/nes }}(\mathrm{R} 2)$ and $\mathrm{CD} 1 \mathrm{~b}^{+} / \mathrm{CD} 33^{+}(\mathrm{R} 3)$ cell population (total MDSC) and $\mathrm{CD}_{1} 4^{+}$monocytic MDSC in one patient. MDSC: Myeloid-derived suppressor cells; FITC: Fluorescein isothiocyanate; PerCP: Peridinin chlorophyll protein complex; PE: Phycoerythrin; APC: Allophycocyanin; CD: Cluster of differentiation; HLA-DR: Human leukocyte antigen. 
(nSS) group (35.6 $\pm 3.2 ; p=0.0322)$ (Figure 2a). However, in case of absolute counts of total MDSCs in peripheral blood of study participants, more significant differences arose. Although the increase of MDSCs in RA group remained $(4383 \pm 456.8 ; \mathrm{p}<0.0001)$, the absolute count of MDSCs increased in sSS group $(3890 \pm 495.7)$ in comparison to control group $(2025 \pm 218.1$; $\mathrm{p}=0.0012$ ). The absolute counts in both groups were also significantly higher compared to pSS group $(2447 \pm 275.1 ; \quad p=0.0002$ and $p=0.0067$, respectively) (Figure $2 b$ ).

The highest frequency of mMDSCs was observed in RA group (2.1 \pm 0.4$)$, but significant differences were established only with pSS and sSS groups $(1.3 \pm 0.3 ; p=0.0141$ and $1.2 \pm 0.4$; 0.0047 , respectively) (Figure 2c). In case of absolute count of mMDSCs, the tendency remained the same - the highest absolute count was observed in RA group $(195.4 \pm 39.0)$, but in this respect, the increase was significant compared to all the other study groups $(86.0 \pm 24.9 ; \mathrm{p}=0.0002$ [pSS], 128.5 $\pm 53.4 ; \mathrm{p}=0.0076$ [sSS], 83.7 \pm 19.0 ; $\mathrm{p}=0.0136$ [nSS]) (Figure 2d).

We also analyzed the distribution of both total and mMDSCs in anti-Ro/SSA and anti-La/SSB positive patients (Table 1), instead of all study participants in pSS group. Even though the $p$ values changed slightly (Figure $3 a-d$ ), no additional significant changes were observed.

In our previous study, we analyzed plasmacytoid (pDC) and conventional dendritic cells (cDC), cytotoxic $\mathrm{T}$ lymphocytes (CTL), natural killer (NK) and natural killer T (NKT) cells ${ }^{18}$ in peripheral blood of the same study subjects as in this study. Consequently, we recalculated correlations and established associations (a)

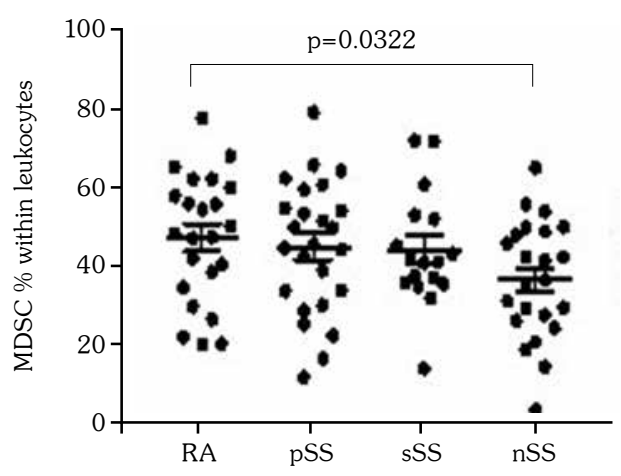

(c)

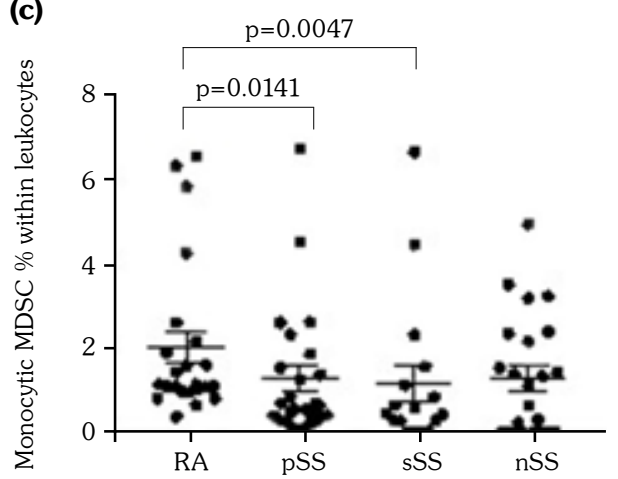

(b)

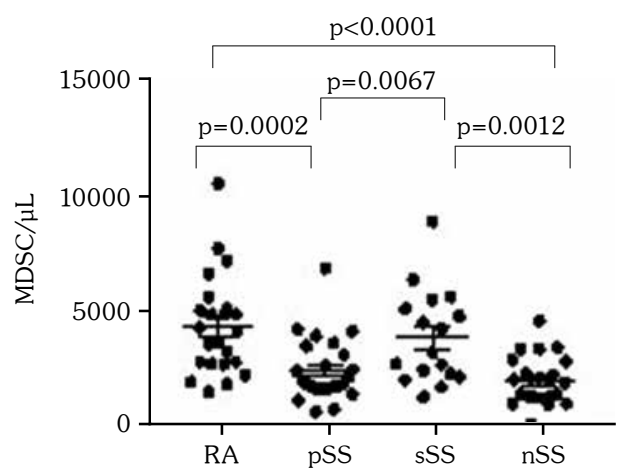

(d)

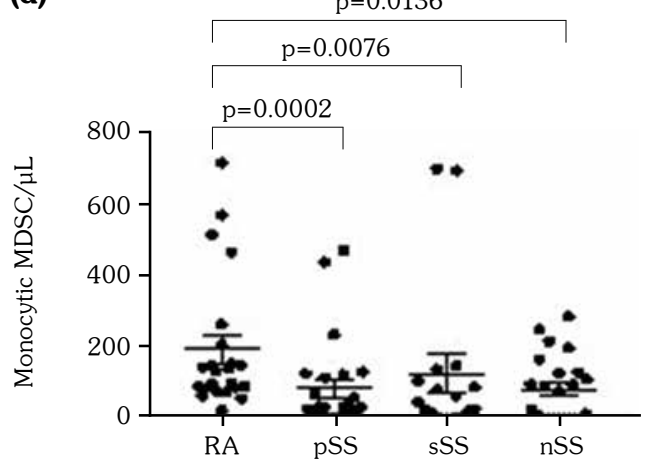

Figure 2. The distribution of total and monocytic MDSC in the peripheral blood of RA, pSS, sSS and nSS patients. $(\mathbf{a}, \mathbf{c})$ Plots indicate frequencies and $(\mathbf{b}, \mathbf{d})$ absolute counts of total and monoctic MDSC, respectively. Each point represents one patient; horizontal lines represent mean value \pm SEM. Analysis was performed by Mann-Whitney U test. MDSC: Myeloid-derived suppressor cells; RA: Rheumatoid arthritis; pSS: Primary Sjögren's syndrome; sSS: Secondary Sjögren's syndrome; nSS: Nonautoimmune sicca syndrome; SEM: Standard error of the mean. 
(a)

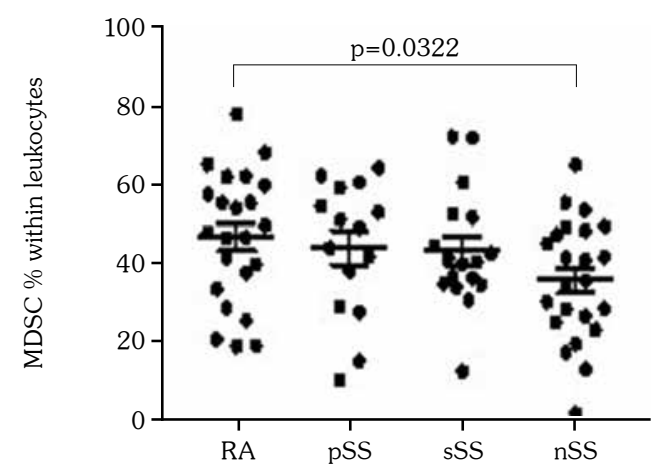

(c)

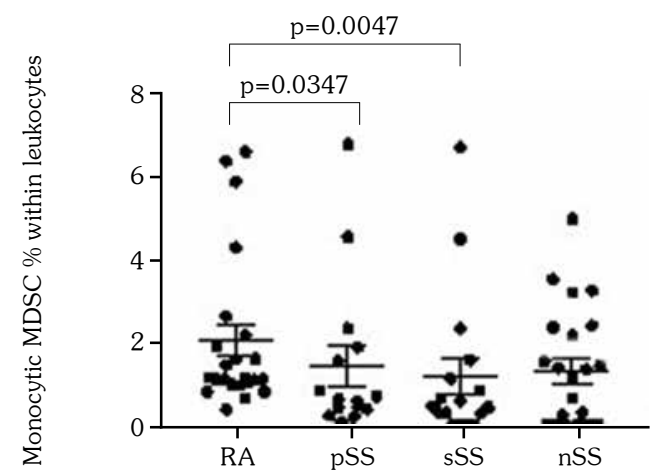

(b)

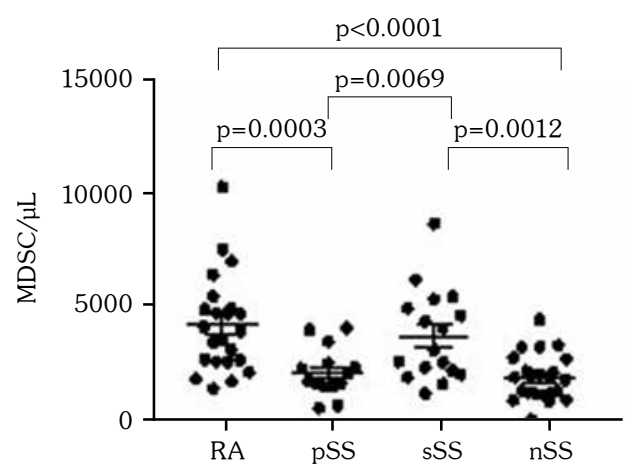

(d)

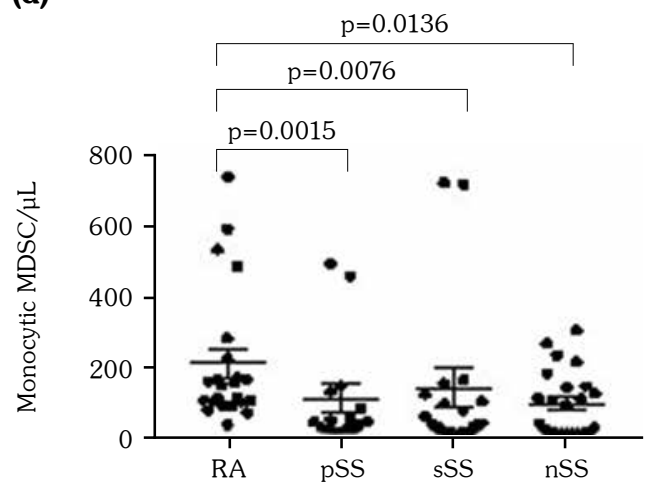

Figure 3. The distribution of total and monocytic MDSC in the peripheral blood of RA, anti-Ro/SSA and anti-La/SSB positive pSS*, sSS and nSS patients. (a, c) Plots indicate frequencies and $(\mathbf{b}, \mathbf{d})$ absolute counts of total and monocytic MDSC, respectively. Each point represents one patient; horizontal lines represent mean value \pm SEM. Analysis was performed by Mann-Whitney U test. MDSC: Myeloid-derived suppressor cells; RA: Rheumatoid arthritis; anti-Ro/SSA: Anti-Sjögren's syndrome type A; anti-La/SSB: Anti-Sjögren's syndrome type B; pSS: Primary Sjögren's syndrome; sSS: Secondary Sjögren's syndrome; nSS: Nonautoimmune sicca syndrome; SEM: Standard error of the mean.

between MDSCs and other peripheral blood cell populations. For this purpose, only the same patient data as for MDSC analysis were selected and correlations were calculated both in frequencies and absolute counts.

We determined that in RA group, the frequency of total MDSCs negatively correlated with $c D C(p=0.0028, r=-0.5948)$. Both the frequency and absolute count of mMDCs also moderately correlated with $\mathrm{cDC}(\mathrm{p}=0.0156$, $r=0.4977$ and $p=0.0362, \quad r=0.4387$, respectively), however, the correlations were positive. Furthermore, correlations between the frequency of total MDSCs and CTL were established ("classical" memory cells $\mathrm{CD}^{\text {high }}{ }^{\mathrm{C}}$ 45RA- $\mathrm{p}=0.0126, \mathrm{r}=-0.5115$; effector memory CTL subtype CD $8^{\text {high }} / 57^{+} / 27^{+} / 45 \mathrm{RA}^{+}$ $p=0.0353, r=0.4407)$.
In sSS group, the frequency and absolute count of total MDSCs positively correlated with CD8 $8^{\text {high }} / 57^{+} / 27 / 45 \mathrm{RA}^{-}$CTL subtype $(\mathrm{p}=0.0406$, $r=0.5007$ and $p=0.0267, r=0.5357$, respectively), while the frequency of mMDSCs negatively correlated only with $\mathrm{CD}^{\text {high }} / 57^{+} / 27^{+} / 45 \mathrm{RA}^{+} \mathrm{CTL}$ subtype ( $p=0.0143, r=-0.5816)$.

In pSS group, both the frequency and absolute count of mMDSCs positively correlated with CD8 high $/ 57 / 27 / 45 R A-C T L$ subtype $(p=0.0425$, $\mathrm{r}=0.4088$ and $0.0249, \mathrm{r}=0.4474$, respectively). The absolute count of mMDSCs also correlated with $\mathrm{cDC}(\mathrm{p}=0.0066, \mathrm{r}=0.5285)$. Correlations with NK and NKT cells were not established in all of the study groups (RA, pSS and sSS); however, in control group, mMDSCs positively correlated with NK cells ( $p=0.0410, r=0.4494)$. 


\section{DISCUSSION}

The bone marrow is stimulated to release MDSCs into the bloodstream to protect the host from harmful excessive immune stimulation in case of acute or chronic infection, and to limit the formation of an autoimmune response to tissue antigens released during injury. The role and molecular mechanisms of MDSCs in human autoimmune diseases are complicated and still unclear. Even though most MDSC studies are carried out in murine models, $9,20,21$ the number of human MDSC studies is increasing. ${ }^{22,23}$ It is already known that MDSCs can inhibit functions of various $\mathrm{T}$ cell populations in many ways. Zhu et al. ${ }^{24}$ demonstrated that in experimental autoimmune encephalomyelitis model, mMDSCs exhibit strong suppressive effect on activated $\mathrm{T}$ cells and participate in $\mathrm{T}$ cell inhibition by producing nitric oxide. Nitric oxide production by MDSCs result in nitrosylation of cysteine residues, which destabilize messenger ribonucleic acid, thus preventing the production of cytokines necessary for $\mathrm{T}$ cell proliferation. ${ }^{25,26}$

There is limited research on the distribution of MDSCs in peripheral blood of patients with autoimmune diseases. In some cases, authors report that in animal models, MDSCs decrease the severity of autoimmune processes, ${ }^{27,28}$ while other studies show that MDSCs are associated with a worse prognosis of the disease. ${ }^{29,30}$ Jiao et al. ${ }^{23}$ determined that in RA patients, circulating MDSC population increased significantly compared to healthy individuals and these findings coincide with our results. Furthermore, they established a negative correlation between MDSCs and Th17 cells, which confirms the association between them. We have also calculated the correlations between MDSCs and other peripheral blood cell populations and found that these cells correlate with $\mathrm{cDC}$ and a few subpopulations of CTL, which also confirms the association between MDSCs and T cells.

For a long time, it has been assumed that $\mathrm{T}$ cells play the main role in SS pathogenesis; however, more recent research claim that B cells are not only crucial in SS pathogenesis, but are also the main cells participating in the development of the disease. ${ }^{31}$ It is also known that there are almost five times more $\mathrm{B}$ cells than $\mathrm{T}$ cells in salivary gland infiltrate of $\mathrm{pSS}$ patients. ${ }^{32}$ The fact that $\mathrm{B}$ cells play the main role in pSS disease may be the reason why we observed significantly increased frequency of total MDSCs only in RA and a significant increase of absolute count of total MDSCs in RA and sSS study groups. In pSS group, the absolute count of both total and mMDSCs was almost the same as in our control group. It is known that anti-Ro/SSA and anti-La/SSB autoantibodies are associated with a more severe course of the disease: earlier onset, decreased salivary flow, more intense eye symptoms, worse Schirmer's test etc. ${ }^{33,34}$ However, after narrowing down pSS group to only anti-Ro/SSA and anti-La/SSB positive patients, results did not change. Nevertheless, we have established a correlation between mMDSC and $\mathrm{CDC}$, as well as a CTL subtype.

Secondary Sjögren's syndrome is a common manifestation in patients with RA, its prevalence varying from 4 to $50 \% .{ }^{35}$ This subgroup of patients has distinct clinical, immunological and genetic profiles. ${ }^{36}$ Observation studies indicate that RA and sSS have different outcomes and patients with sSS have two-fold higher risk of non-Hodgkin's lymphoma and higher mortality rate. ${ }^{37}$ In our study, we have determined that total MDSCs in sSS increased, compared to pSS and nSS and were comparable to RA; however, mMDSCs in sSS increased only slightly and were comparable to pSS and nSS. It is known that granulocytic and monocytic MDSCs have distinct molecular properties and distinct gene expression profiles but also opposing effects on tumor cells. ${ }^{38}$ This can also be assumed in terms of autoimmune diseases. Our presumption is that granulocytic MDSCs play a more significant role in both RA and sSS. Moreover, in this group, we established correlations between total and mMDSCs and different CTL subpopulations.

One of the downfalls of our study is that we only measured the distribution of MDSCs and mMDSCs in RA, pSS and sSS study groups. We observed increased frequency of total MDSCs in all study groups compared to control group, yet the frequency of mMDSCs increased only in RA group. Due to the differences between total and mMDSC populations, further and more extensive studies of MDSC subpopulations should be conducted, distinguishing granulocytic $\mathrm{CD} 15^{+}$ MDSCs and other subpopulations. Furthermore, larger sample sizes are required. Different factors 
(prostaglandins, cyclooxygenase-2, interleukin 6, granulocyte-macrophage colony-stimulating factor, macrophage colony-stimulating factor, interferon gamma, transforming growth factor beta and tumor necrosis factor) are responsible for MDSC expansion, proliferation and inhibition of differentiation into mature cells. ${ }^{39-42}$ Assessment of serum factor levels of study patients might give us an insight as to why there is such a difference in MDSC distribution between these two autoimmune diseases (RA and pSS).

In conclusion, we have determined that the most prominent increase of both total and mMDSCs was evident in RA and sSS groups, which leads us to believe that MDSCs are associated with rheumatic processes. Furthermore, to the best of our knowledge, this is the first study to analyze the distribution of MDSCs in peripheral blood of pSS and sSS patients and to compare the results with RA.

\section{Declaration of conflicting interests}

The authors declared no conflicts of interest with respect to the authorship and/or publication of this article.

\section{Funding}

This work was supported by a grant with No. MIP013/2014 from the Research Council of Lithuania and by State Research Institute Centre for Innovative Medicine.

\section{REFERENCES}

1. Bronte V. Myeloid-derived suppressor cells in inflammation: uncovering cell subsets with enhanced immunosuppressive functions. Eur $\mathrm{J}$ Immunol 2009;39:2670-2.

2. Solito S, Falisi E, Diaz-Montero CM, Doni A, Pinton $\mathrm{L}$, Rosato $\mathrm{A}$, et al. A human promyelocytic-like population is responsible for the immune suppression mediated by myeloid-derived suppressor cells. Blood 2011;118:2254-65.

3. Condamine T, Gabrilovich DI. Molecular mechanisms regulating myeloid-derived suppressor cell differentiation and function. Trends Immunol 2011;32:19-25.

4. Greten TF, Manns MP, Korangy F. Myeloid derived suppressor cells in human diseases. Int Immunopharmacol 2011;11:802-7.

5. Gallina G, Dolcetti L, Serafini P, De Santo C, Marigo I, Colombo MP, et al. Tumors induce a subset of inflammatory monocytes with immunosuppressive activity on $\mathrm{CD} 8+\mathrm{T}$ cells.J
Clin Invest 2006;116:2777-90.

6. Zhao F, Obermann S, von Wasielewski R, Haile L, Manns MP, Korangy F, et al. Increase in frequency of myeloid-derived suppressor cells in mice with spontaneous pancreatic carcinoma. Immunology 2009; 128:141-9.

7. Ji J, Xu J, Zhao S, Liu F, Qi J, Song Y, et al. Myeloid-derived suppressor cells contribute to systemic lupus erythaematosus by regulating differentiation of Th17 cells and Tregs. Clin Sci (Lond) 2016;130:1453-67.

8. Yin B, Ma G, Yen CY, Zhou Z, Wang GX, Divino $\mathrm{CM}$, et al. Myeloid-derived suppressor cells prevent type 1 diabetes in murine models. J Immunol 2010;185:5828-34.

9. Sander LE, Sackett SD, Dierssen U, Beraza N, Linke RP, Müller M, et al. Hepatic acute-phase proteins control innate immune responses during infection by promoting myeloid-derived suppressor cell function. J Exp Med 2010;207:1453-64.

10. Lei AH, Yang Q, Cai WP, Liu YF, Lan Y, Qin AP, et al. Clinical Significance of Myeloid-Derived Suppressor Cells in Human Immunodeficiency Virus1/ Hepatitis C Virus-coinfected Patients. Scand J Immunol 2016;83:438-44.

11. du Plessis N, Loebenberg L, Kriel M, von GrooteBidlingmaier F, Ribechini E, Loxton AG, et al. Increased frequency of myeloid-derived suppressor cells during active tuberculosis and after recent mycobacterium tuberculosis infection suppresses T-cell function. Am J Respir Crit Care Med 2013;188:724-32.

12. Schmid M, Zimara N, Wege AK, Ritter U. Myeloidderived suppressor cell functionality and interaction with Leishmania major parasites differ in C57BL/6 and BALB/c mice. Eur J Immunol 2014;44:3295306.

13. Brudecki L, Ferguson DA, McCall CE, El Gazzar M. Myeloid-derived suppressor cells evolve during sepsis and can enhance or attenuate the systemic inflammatory response. Infect Immun 2012;80:2026-34.

14. Bunt SK, Clements VK, Hanson EM, Sinha P, OstrandRosenberg S. Inflammation enhances myeloid-derived suppressor cell cross-talk by signaling through Toll-like receptor 4. J Leukoc Biol 2009;85:996-1004.

15. Highfill SL, Rodriguez PC, Zhou Q, Goetz CA, Koehn BH, Veenstra R, et al. Bone marrow myeloidderived suppressor cells (MDSCs) inhibit graft-versushost disease (GVHD) via an arginase-1-dependent mechanism that is up-regulated by interleukin-13 Blood 2010;116:5738-47.

16. Fujii W, Ashihara E, Hirai H, Nagahara H, Kajitani $\mathrm{N}$, Fujioka K, et al. Myeloid-derived suppressor cells play crucial roles in the regulation of mouse collageninduced arthritis. J Immunol 2013;191:1073-81.

17. Seror R, Ravaud P, Bowman SJ, Baron G, Tzioufas $\mathrm{A}$, Theander E, et al. EULAR Sjogren's syndrome disease activity index: development of a consensus 
systemic disease activity index for primary Sjogren's syndrome. Ann Rheum Dis 2010;69:1103-9.

18. Radner H, Neogi T, Smolen JS, Aletaha D. Performance of the 2010 ACR/EULAR classification criteria for rheumatoid arthritis: a systematic literature review. Ann Rheum Dis 2014;73:114-23.

19. Narkeviciute I, Sudzius G, Mieliauskaite D, Mackiewicz $\mathrm{Z}$, Butrimiene I, Viliene $\mathrm{R}$, et al. Are cytotoxic effector cells changes in peripheral blood of patients with Sjögren's syndrome related to persistent virus infection: Suggestions and conundrums. Cell Immunol 2016;310:123-30.

20. Cripps JG, Wang J, Maria A, Blumenthal I, Gorham JD. Type $1 \mathrm{~T}$ helper cells induce the accumulation of myeloid-derived suppressor cells in the inflamed Tgfb1 knockout mouse liver. Hepatology 2010;52:1350-9.

21. Kurkó J, Vida A, Ocskó T, Tryniszewska B, Rauch TA, Glant TT, et al. Suppression of proteoglycan-induced autoimmune arthritis by myeloid-derived suppressor cells generated in vitro from murine bone marrow. PLoS One 2014;9:111815.

22. Kurkó J, Vida A, Glant TT, Scanzello CR, Katz RS, Nair A, et al. Identification of myeloid-derived suppressor cells in the synovial fluid of patients with rheumatoid arthritis: a pilot study. BMC Musculoskelet Disord 2014;15:281.

23. Jiao Z, Hua S, Wang W, Wang H, Gao J, Wang $\mathrm{X}$. Increased circulating myeloid-derived suppressor cells correlated negatively with Th17 cells in patients with rheumatoid arthritis. Scand J Rheumatol 2013;42:85-90.

24. Zhu B, Bando Y, Xiao S, Yang K, Anderson AC, Kuchroo VK, et al. CD11b+Ly-6C(hi) suppressive monocytes in experimental autoimmune encephalomyelitis. J Immunol 2007;179:5228-37.

25. Crook KR, Liu P. Role of myeloid-derived suppressor cells in autoimmune disease. World $\mathrm{J}$ Immunol 2014;4:26-33.

26. Bronte V, Zanovello P. Regulation of immune responses by L-arginine metabolism. Nat Rev Immunol 2005;5:641-54.

27. Ioannou M, Alissafi T, Lazaridis I, Deraos G, Matsoukas J, Gravanis A, et al. Crucial role of granulocytic myeloid-derived suppressor cells in the regulation of central nervous system autoimmune disease. J Immunol 2012;188:1136-46.

28. Haile LA, von Wasielewski R, Gamrekelashvili J, Krüger C, Bachmann O, Westendorf AM, et al. Myeloid-derived suppressor cells in inflammatory bowel disease: a new immunoregulatory pathway. Gastroenterology 2008;135:871-81.

29. King IL, Dickendesher TL, Segal BM. Circulating Ly-6C+ myeloid precursors migrate to the CNS and play a pathogenic role during autoimmune demyelinating disease. Blood 2009;113:3190-7.

30. Yi H, Guo C, Yu X, Zuo D, Wang XY. Mouse CD11b+Gr-1+ myeloid cells can promote Th17 cell differentiation and experimental autoimmune encephalomyelitis. J Immunol 2012;189:4295-304.

31. Cornec D, Devauchelle-Pensec V, Tobón GJ, Pers JO, Jousse-Joulin S, Saraux A. B cells in Sjögren's syndrome: from pathophysiology to diagnosis and treatment. J Autoimmun 2012;39:161-7.

32. Hernández-Molina G, Avila-Casado C, CárdenasVelázquez F, Hernández-Hernández C, Calderillo ML, Marroquín V, et al. Similarities and differences between primary and secondary Sjögren's syndrome. J Rheumatol 2010;37:800-8.

33. Toker E, Yavuz S, Direskeneli H. Anti-Ro/SSA and anti-La/SSB autoantibodies in the tear fluid of patients with Sjögren's syndrome. $\mathrm{Br} \mathrm{J}$ Ophthalmol 2004;88:384-7.

34. Ramos-Casals M, Solans R, Rosas J, Camps MT, Gil A, Del Pino-Montes J, et al. Primary Sjögren syndrome in Spain: clinical and immunologic expression in 1010 patients. Medicine (Baltimore) 2008;87:210-9.

35. Theander E, Jacobsson LT. Relationship of Sjögren's syndrome to other connective tissue and autoimmune disorders. Rheum Dis Clin North Am 2008;34:935-47.

36. He J, Ding Y, Feng M, Guo J, Sun X, Zhao J, et al. Characteristics of Sjögren's syndrome in rheumatoid arthritis. Rheumatology (Oxford) 2013;52:1084-9.

37. Kauppi M, Pukkala E, Isomäki $H$. Elevated incidence of hematologic malignancies in patients with Sjögren's syndrome compared with patients with rheumatoid arthritis (Finland). Cancer Causes Control 1997;8:201-4.

38. Ouzounova M, Lee E, Piranlioglu R, El Andaloussi A, Kolhe R, Demirci MF, et al. Monocytic and granulocytic myeloid derived suppressor cells differentially regulate spatiotemporal tumour plasticity during metastatic cascade. Nat Commun 2017;8:14979.

39. Fujio K, Okamura T, Sumitomo S, Yamamoto K. Regulatory $\mathrm{T}$ cell-mediated control of autoantibodyinduced inflammation. Front Immunol 2012;3:28.

40. Serafini P, Carbley R, Noonan KA, Tan G, Bronte $\mathrm{V}$, Borrello I. High-dose granulocyte-macrophage colony-stimulating factor-producing vaccines impair the immune response through the recruitment of myeloid suppressor cells. Cancer Res 2004;64:6337-43.

41. Sinha P, Clements VK, Fulton AM, Ostrand-Rosenberg S. Prostaglandin E2 promotes tumor progression by inducing myeloid-derived suppressor cells. Cancer Res 2007;67:4507-13.

42. Corzo CA, Cotter MJ, Cheng P, Cheng F, Kusmartsev $\mathrm{S}$, Sotomayor $\mathrm{E}$, et al. Mechanism regulating reactive oxygen species in tumor-induced myeloid-derived suppressor cells. J Immunol 2009;182:5693-701. 